\title{
إشكالية المنهج في تعليم اللغة العربية للناطقين بغيرها
}

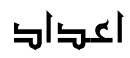 \\ العربيه الحضغراوي جإئي \\ كلية الآداب والعلوم الإنسانية جامعة محمد الخامس الرباط
}

Doi: 10.12816/jnal.2020.69603

r.19/1./rr : الاستلام

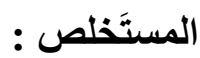

لقد كانت المناهج التعليمية ـو لا تز ال ـأهم جهة مستهدفة للإصلاح و التغيير و التطوير

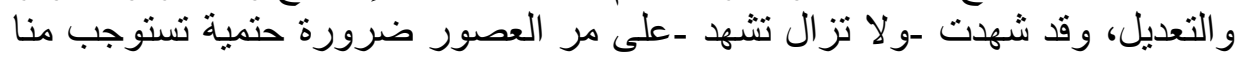

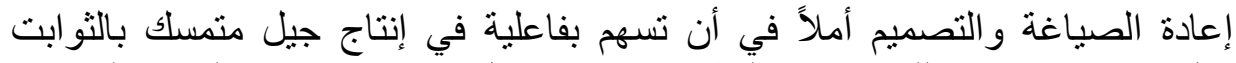

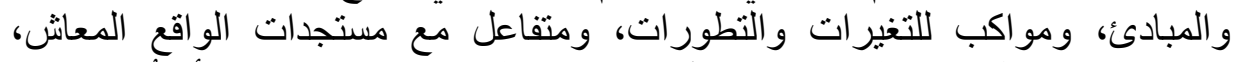

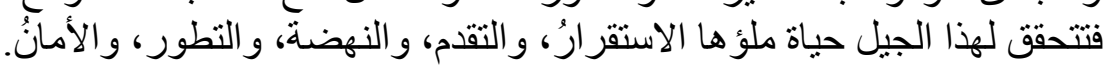

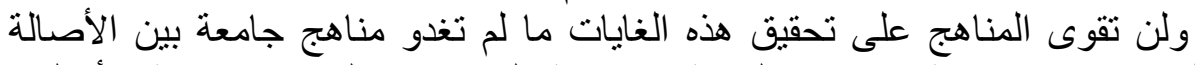

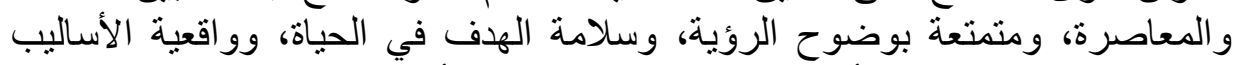

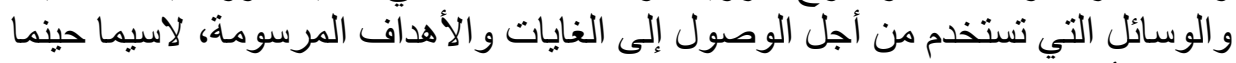

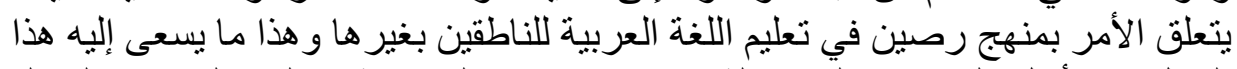

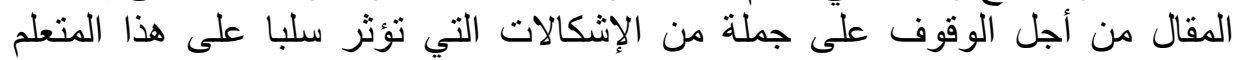
الكلمات المفتاحية: عملية التلقين، عملية التعليم، البيئة التعليمية، جودة العملية التعليمية. Abstract:

The educational curricula have been - and still are - the most important target for reform, change, development and modification. With the advances of living reality, a generation full of stability, progress, renaissance, development and safety is achieved for this generation. The curriculum will not be able to achieve these goals unless it becomes an inclusive curriculum between authenticity and modernity, with clear vision, integrity of purpose in life, and realistic methods and means used to reach the goals and objectives set, especially when it comes to a discreet 
approach in teaching Arabic to non-Arabic speakers. This article seeks to identify a number of problems that negatively affect this learner of Arabic.

Keywords: indoctrination process, teaching process, learning environment, quality of educational process.

لقدمة: أصبح يشكل مفهوم تدريس اللغة العربية للناطقين بغير ها من المفاهيم الرئيسة

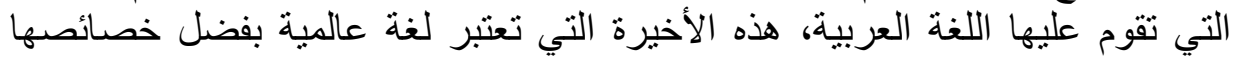

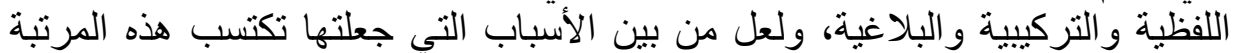

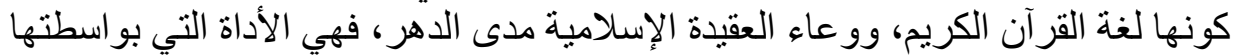

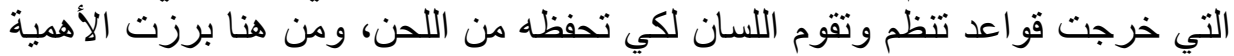

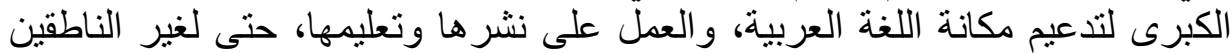

إن إن المعلم اليوم عند تعليمه للأجنبي خصائص ومميز ات اللغة العربية، ليجد نفسه أمام

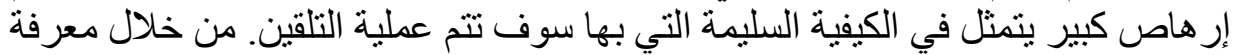

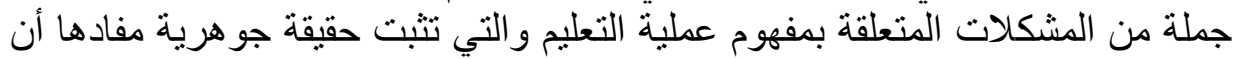

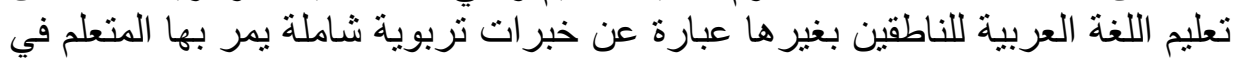

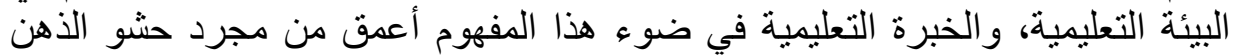
بالمعلو مات و الحقائق.

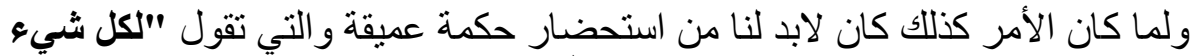

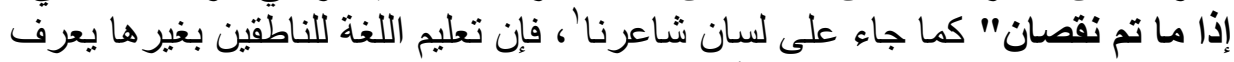

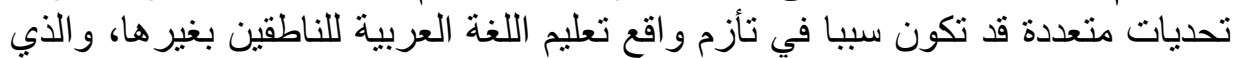

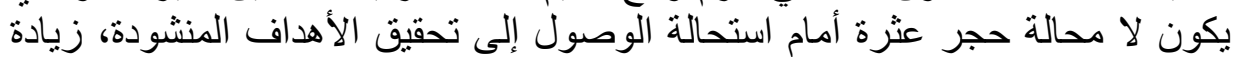

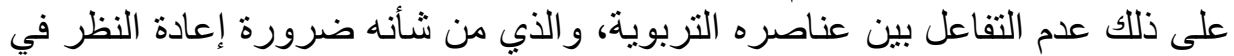

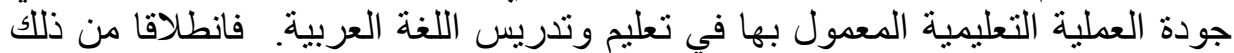

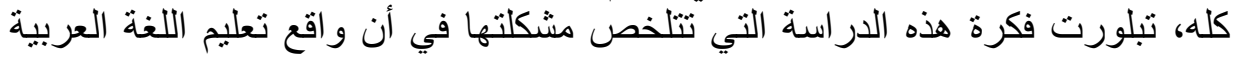

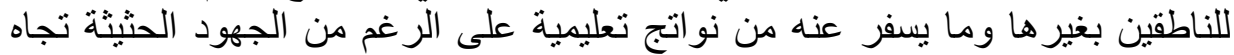

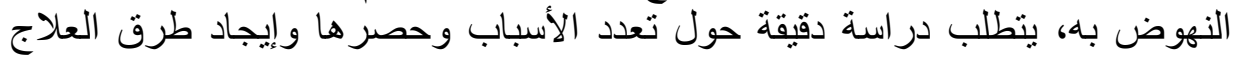

' لأبي البقاء الرندي في مرثيته الثهيرة في الأندلس حيث قال:

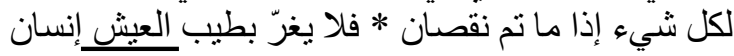




\section{المجلد لثالث - العلد (§) يناير بr.r}

\section{مجالة الناطقين بفير اللفة العربية}

المناسبة لها، عبر وسائل ممنهجة تكون كفيلة في تحسين واقع العملية التعليمية وفق إنق

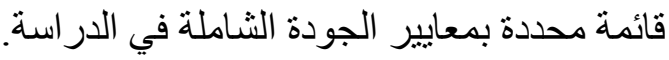

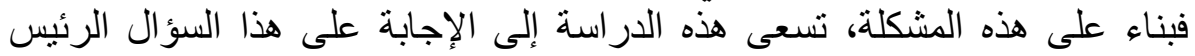

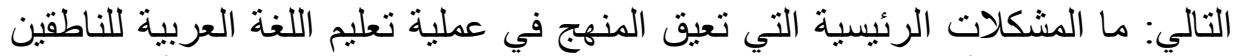

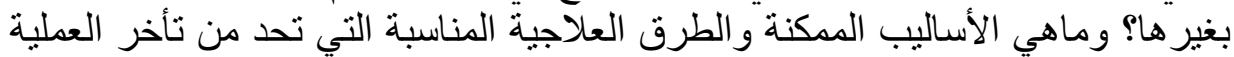

التعليمية التعلمية؟ مشكلة البحث

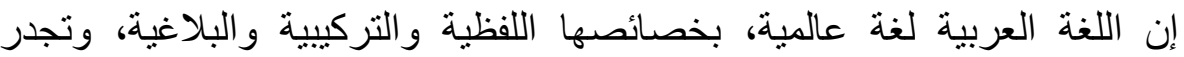

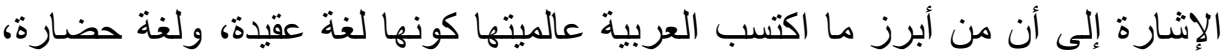

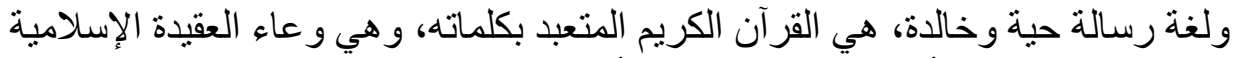

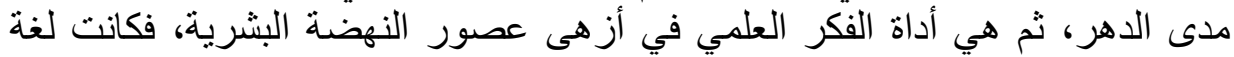

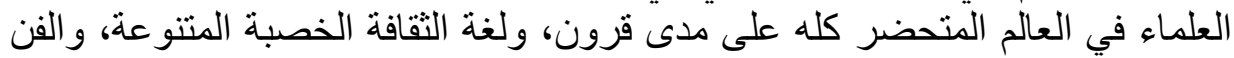

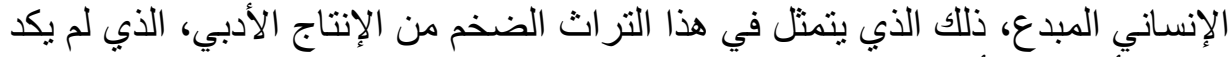

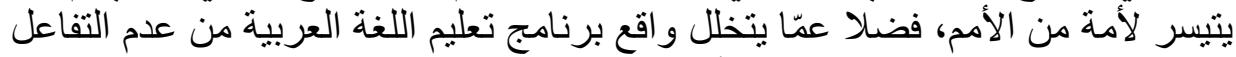

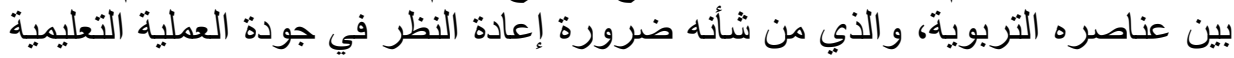

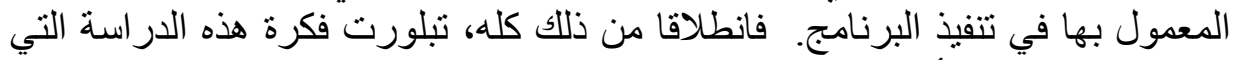

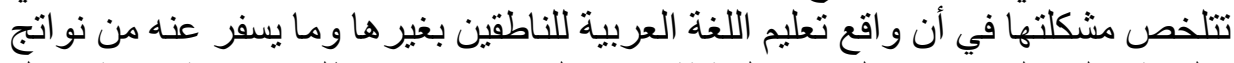

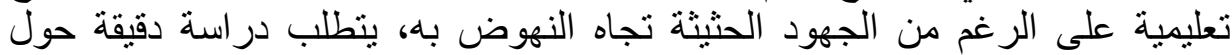
اعتماد منهج رصين في و اقع العملية التعليمية لتعلم اللغة العربية للناطقين بغير ها. أهداف الدراسة

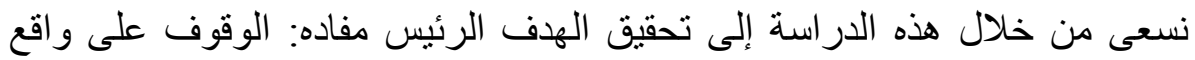

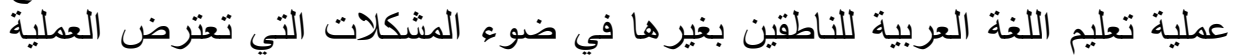

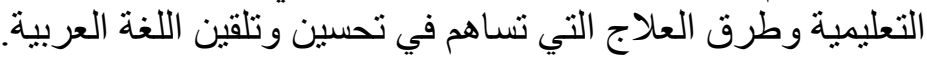

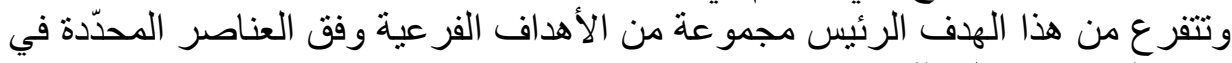

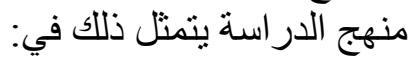

1. العمل على تحديد المشكلات الأساسية التي يعاني منها الأجانب لتعلم اللغة العربية.

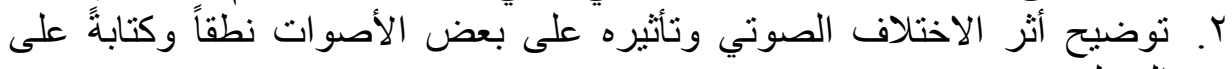
المتعلم

r. معرفة المشكلات التي تو اجه المعلم القائم على تدريس اللغة العربية للناطقين بغير ها

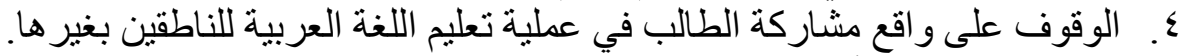

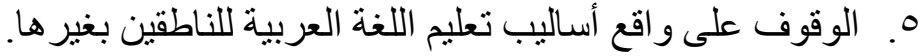

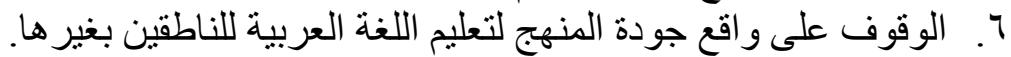




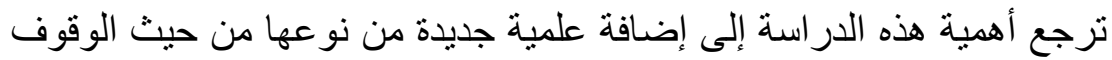

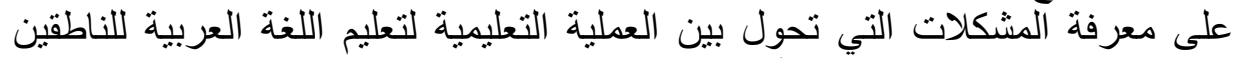

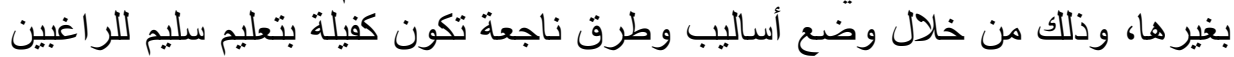

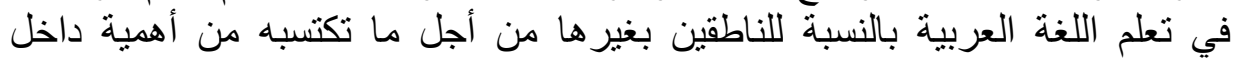

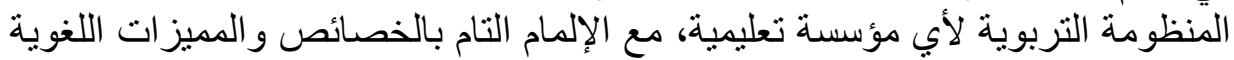

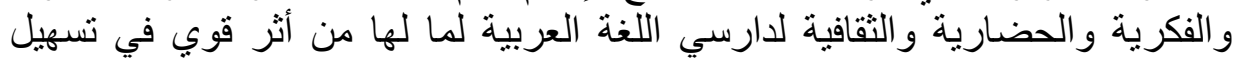

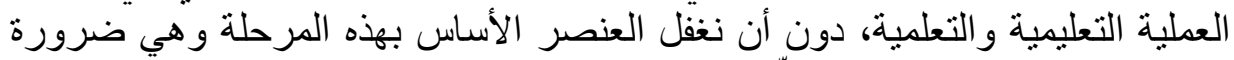

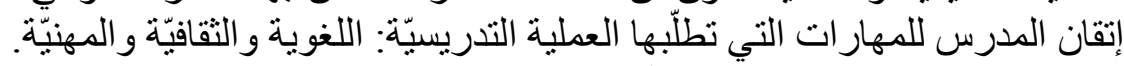

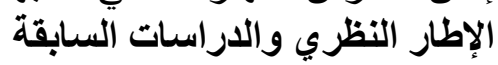

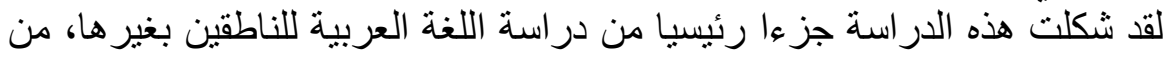

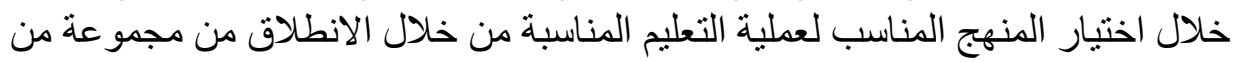

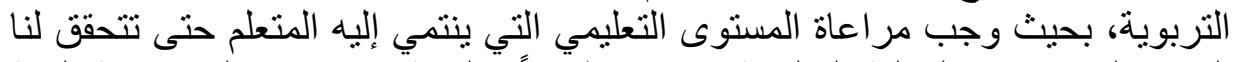

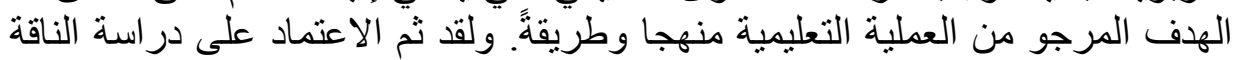

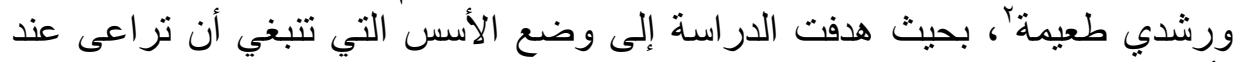

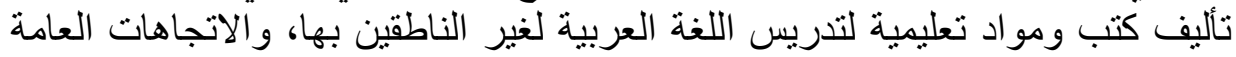

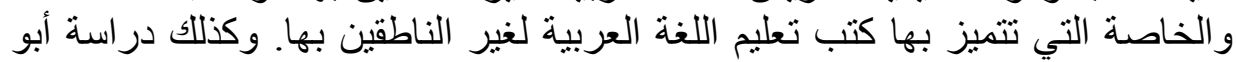

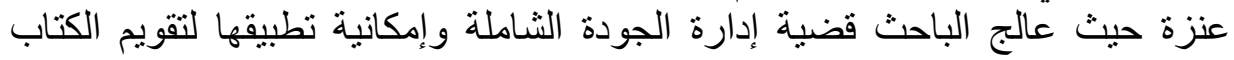

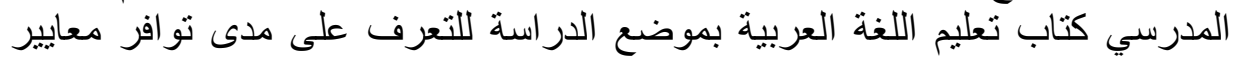

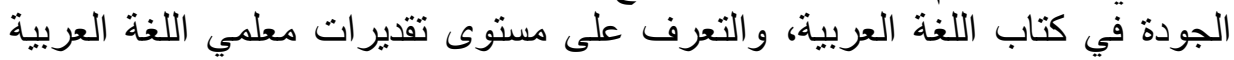

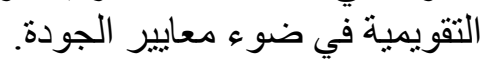

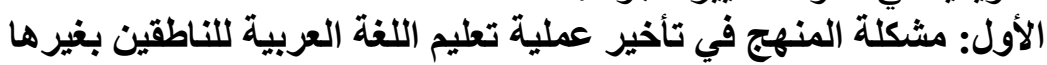

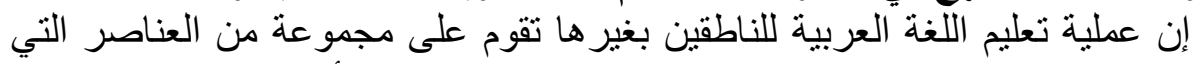

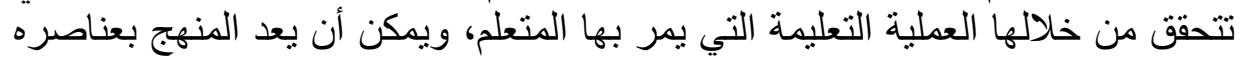

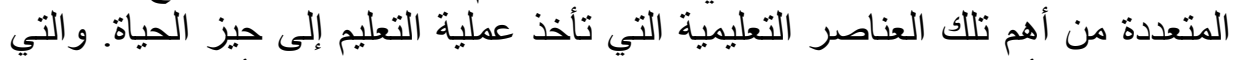

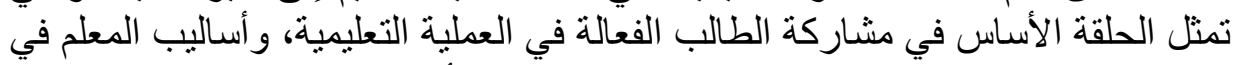

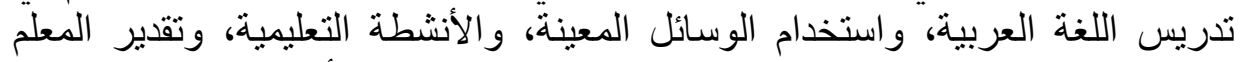

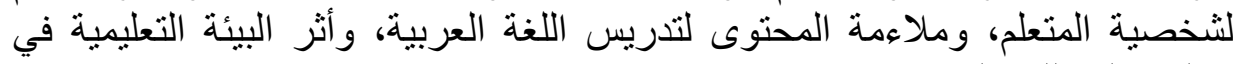
فعالية تعليم اللغة العربية.

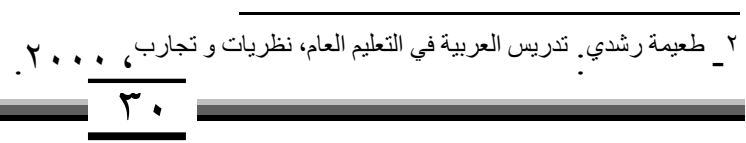


و الملاحظ أثناء العملية التعليمية وجود فروق كبيرة بين تعليم اللغة لأبنائها، وتعليمها

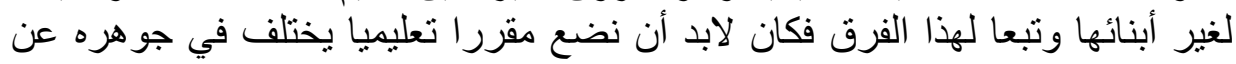

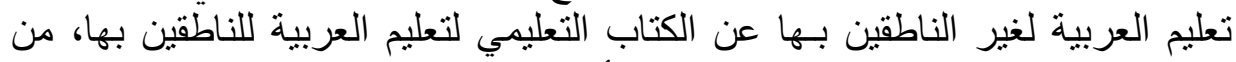

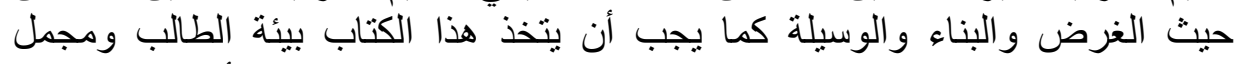

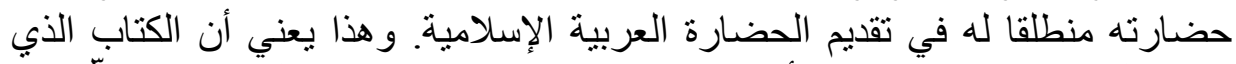

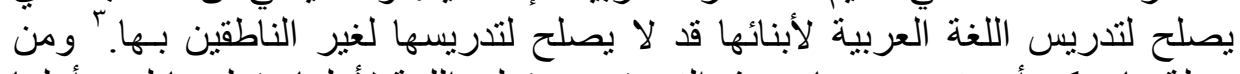

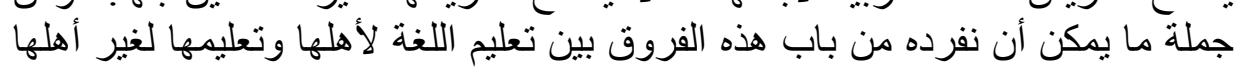
نذكر:

\begin{tabular}{|c|c|}
\hline الناطقين بغير اللغة العربية & الناطقين باللغة العربية \\
\hline التعلعمية. من الصفر في المؤسسة & 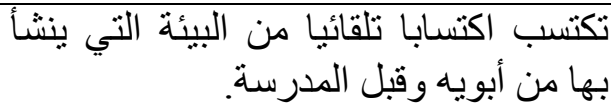 \\
\hline لا يعيش ثقافتها خصو لا ينطق اللغة العربية من يتعلمها & يعيش ثقافتها ويكتسب \\
\hline المؤستسة أن التعليمية. جميع المهار ات في & 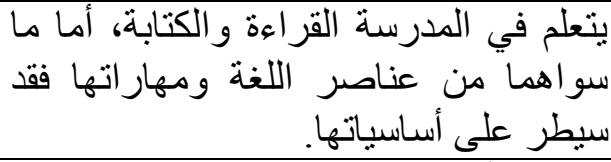 \\
\hline يجهل كل هذا ويحتاج إلى تعلمه كله. & 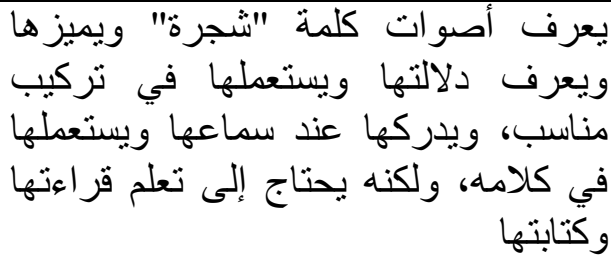 \\
\hline
\end{tabular}

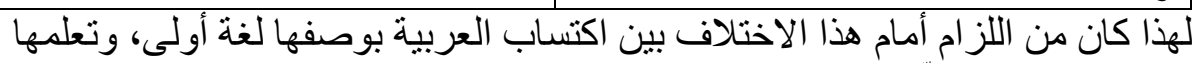

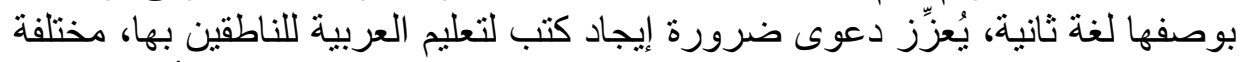

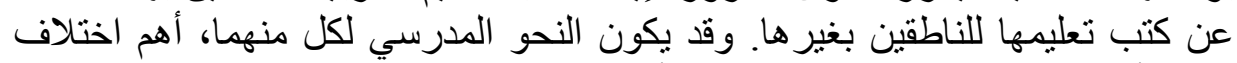

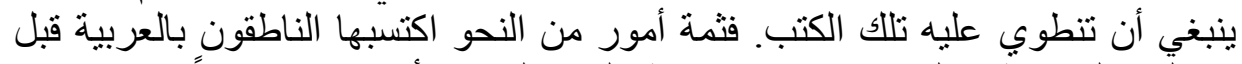

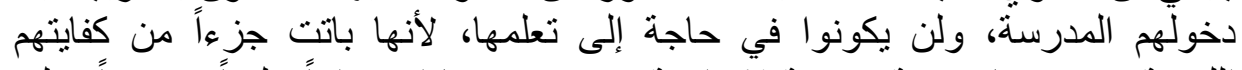

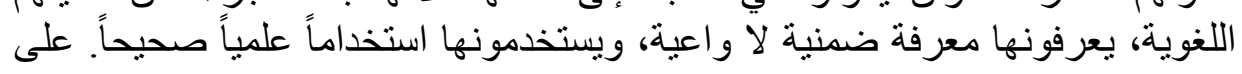

r - علي محمد القاسمي: اتجاهات حديثة في تعليم اللغة العربية للناطقين باللغات الأخرى، عمادة

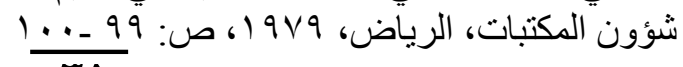
rI 


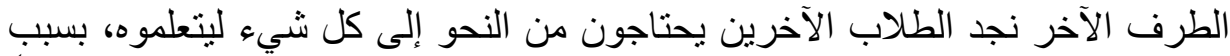

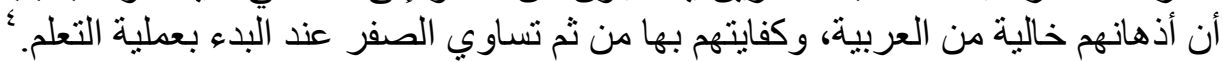

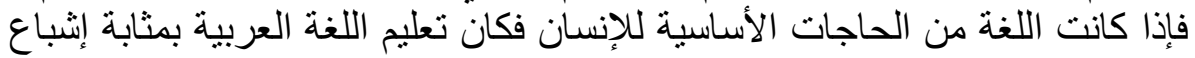

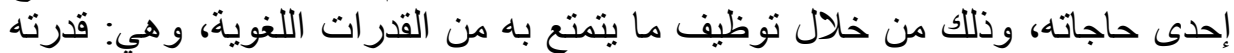

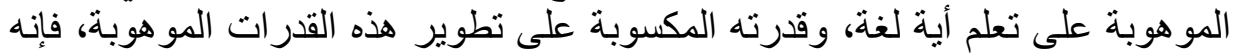

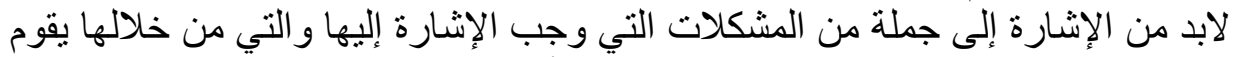

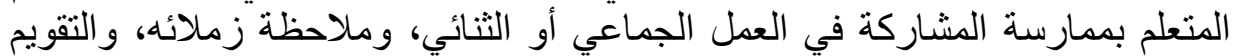

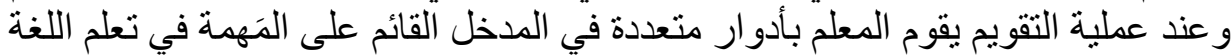

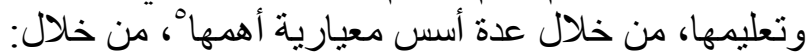

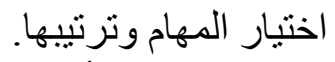
تهيئة المتعلمين لأداء المَهمة.

لفت انتباه المتعلمين إلى الصيغة الصنية اللغوية المستهدفة.

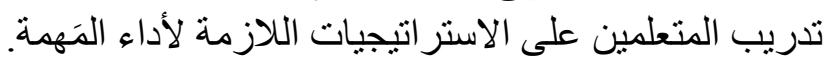
توجيه المتعلمين في أثناء أداء المَهمة.

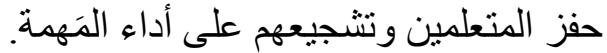
تقديم المساعدة و العون عند الحاجة.

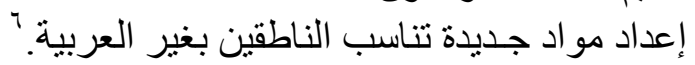

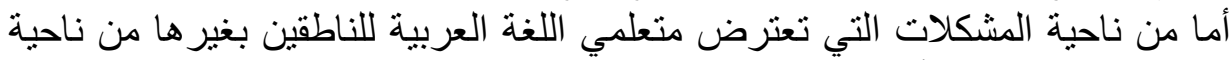

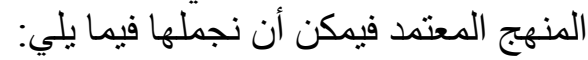
مشكلات عند تعلم النظام الصوتي للغنة العربية. مشكلات عند تعلم النظام النحوي للغة العنام العربية.

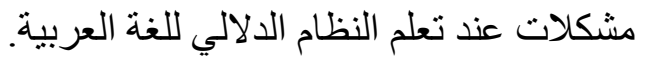
مشكلات في فهم ثقافة اللغة العربية. مشكلات و هم يتعلمون مهار ات الاستماع باللغة فئة العربية.

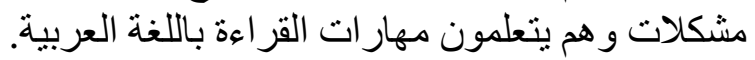
مشكلات وهم يتعلمون مهار ات الحديث باللغة العربة العربية.

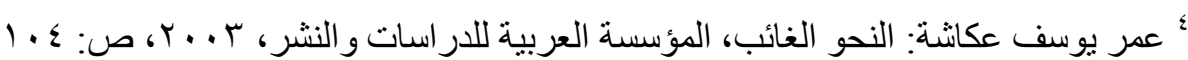
5 Oxford, R. L :Task-Based Language Teaching and Learning: An Overview. 2006.

7 عبد الرحمن بن إبراهيم الفوزان: مذكرة إعداد مواد تعليم اللغة العربية لغير الناطقين بهها،

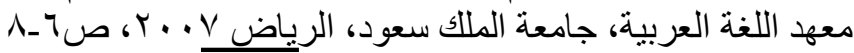




\section{مشكلات و هم يتعلمون مهار ات الكتابة باللغة العربية.}

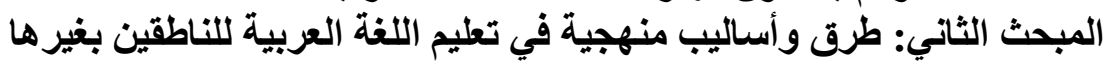

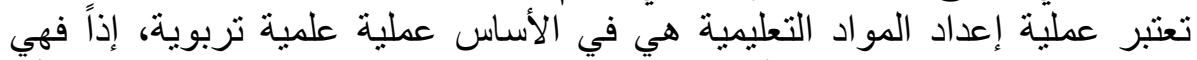

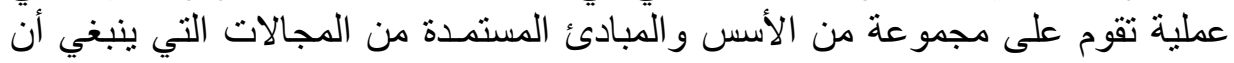

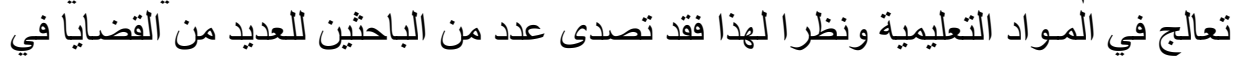

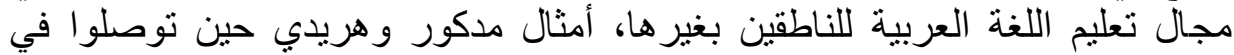

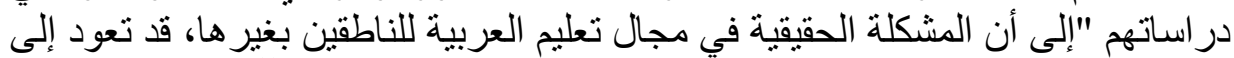

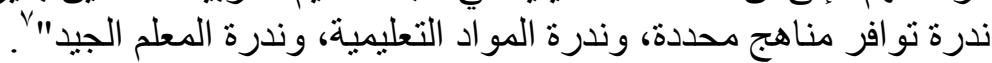

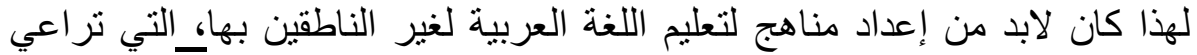

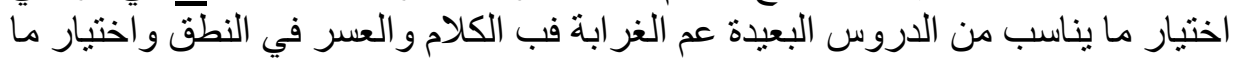

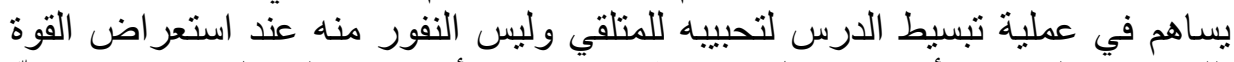

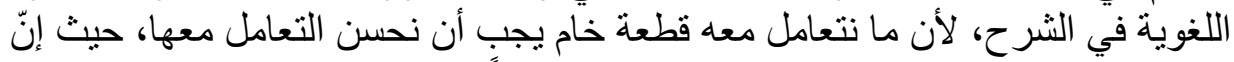

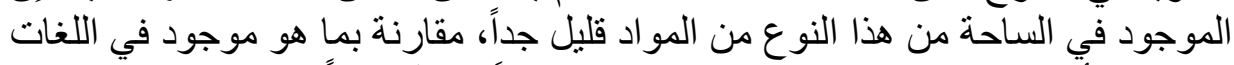

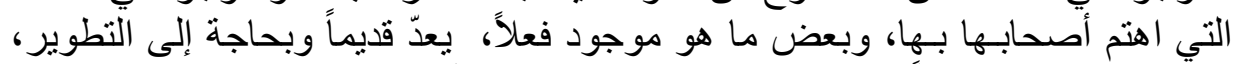

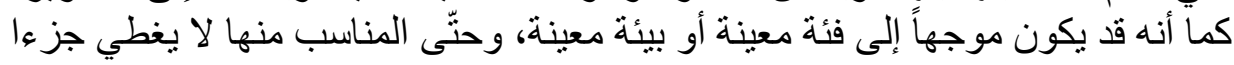
يسير ا من الحاجة القائمة.

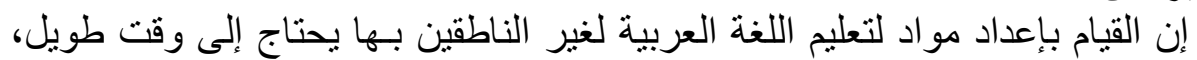

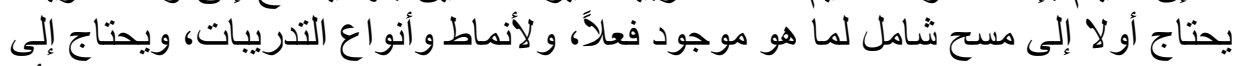

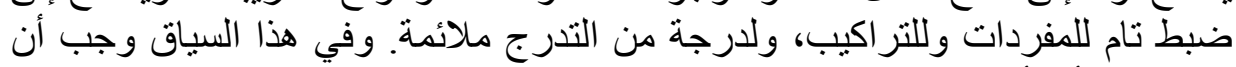

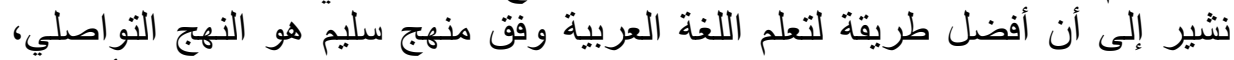

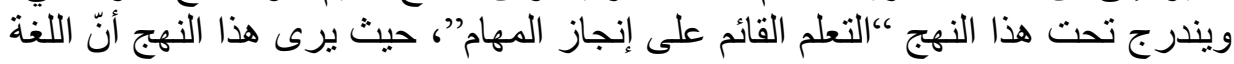

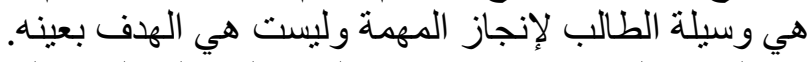

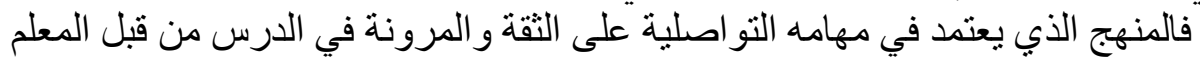

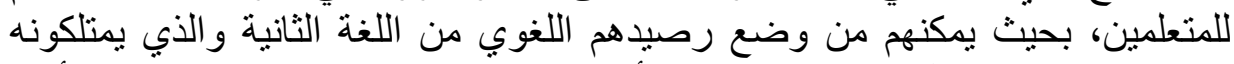

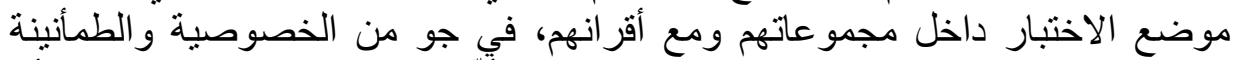

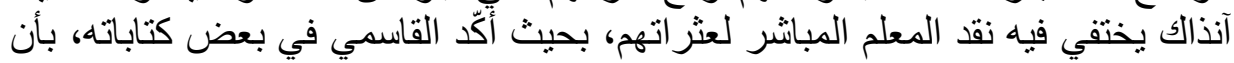

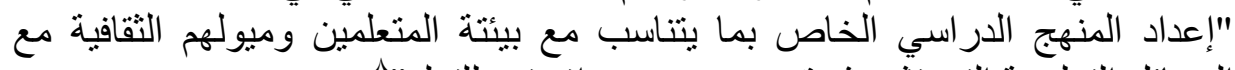

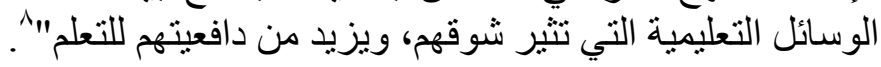

" ـ مدكور علي أحمد، وهريدي إيمان أحمد: تعليم اللغة العربية لغير الناطقين بها، النظرية

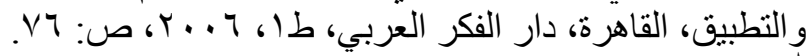

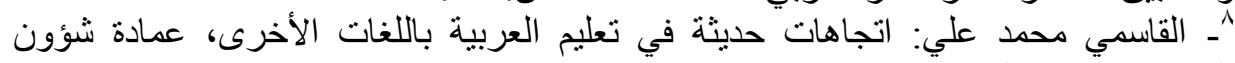

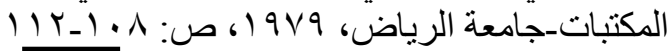
rr 


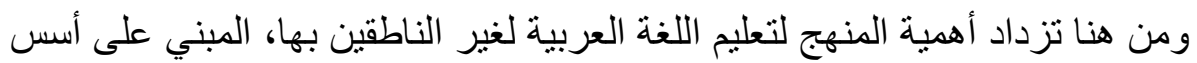

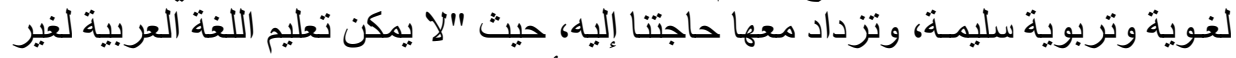

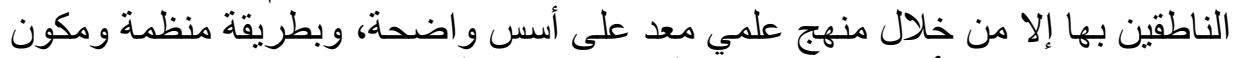

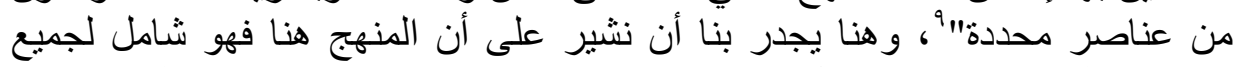

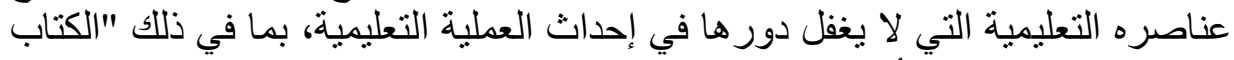

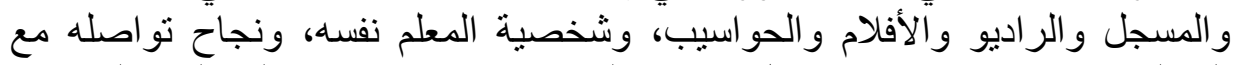

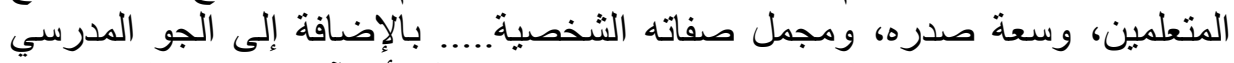

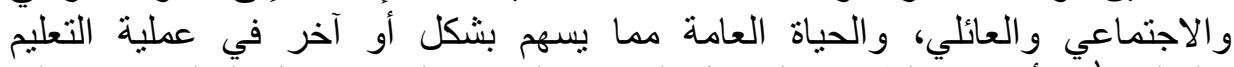

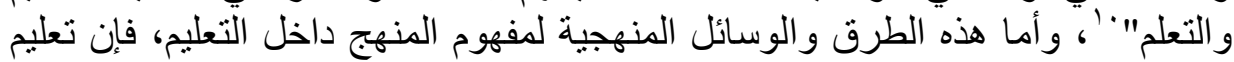

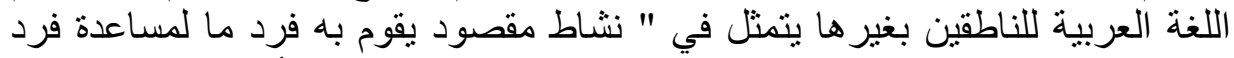

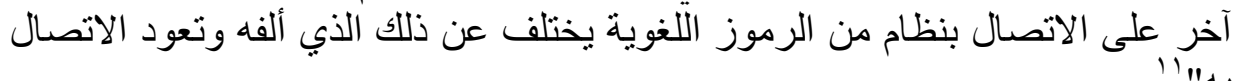
ولكي نقون بتقريب الصورة أكثر لفاعلية المنهج في اختيار المقرر الأنسب للتعلم لابد

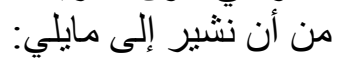

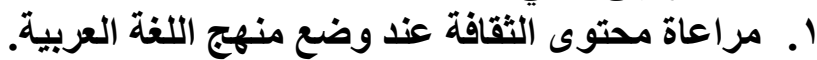

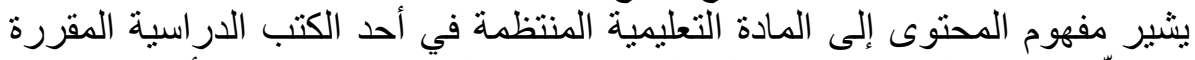

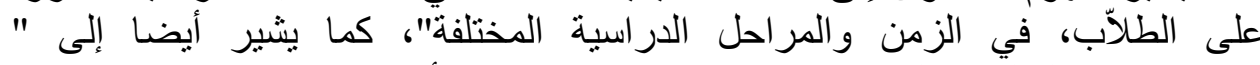

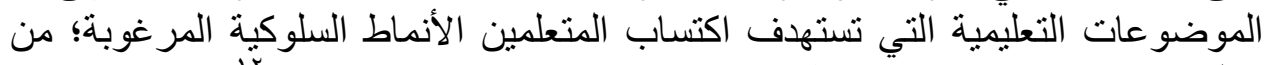

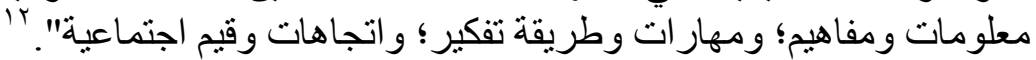

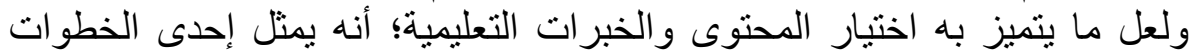

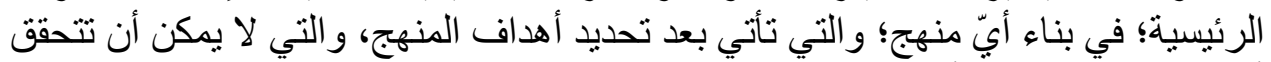

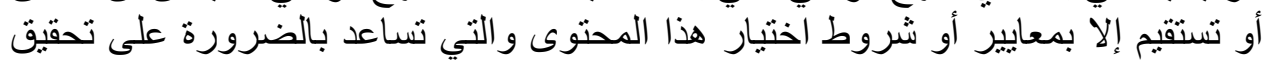
أهداف عديدة من جملتها:

9 ـ مدكور علي أحمد، هريدي إيمان أحمد: تعليم اللغة العربية لغير الناطقين بها، النظرية

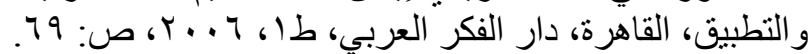

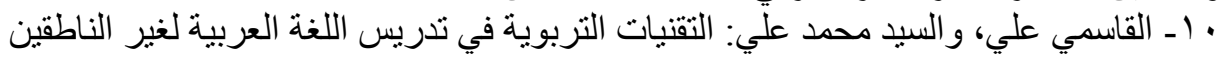

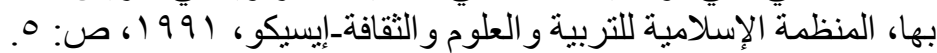

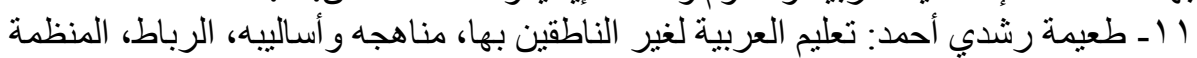

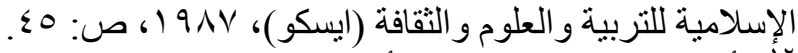

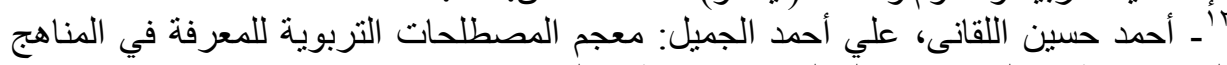

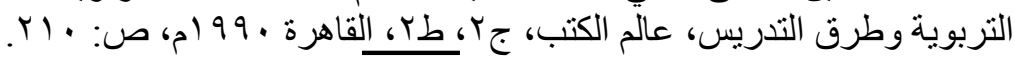


ا ـ الصــدق: Validity و الذي يمثل العلاقة بين المحتوى والأهداف التي يرجى تحققها.

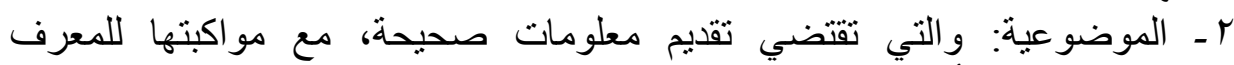

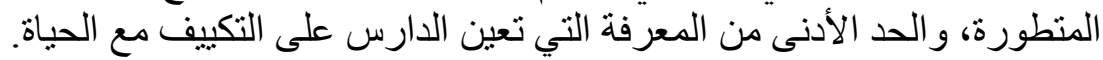

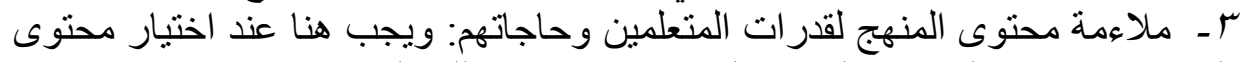

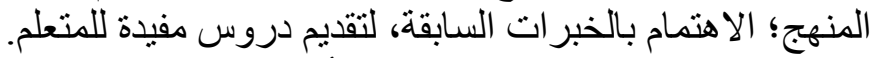

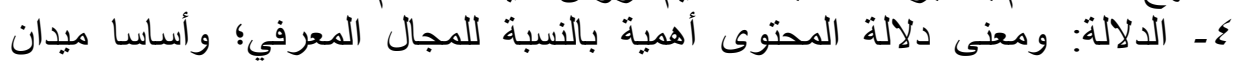

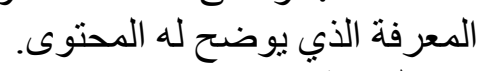

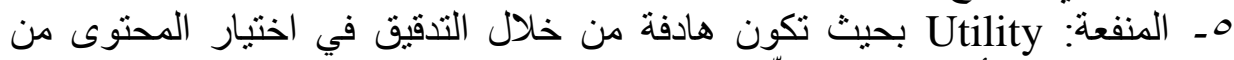

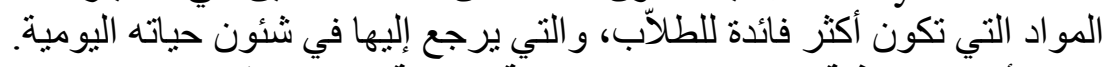

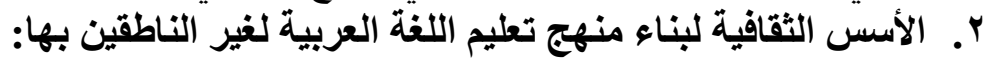

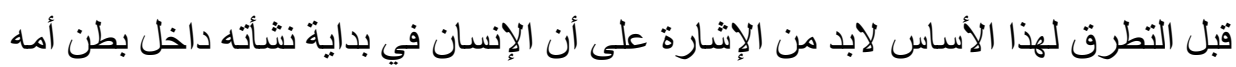

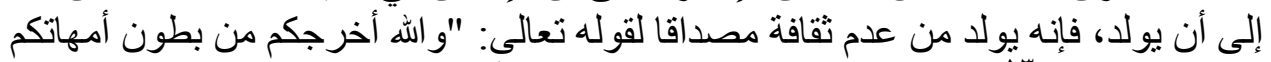

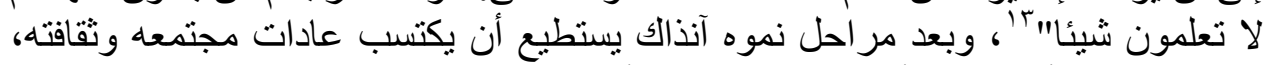

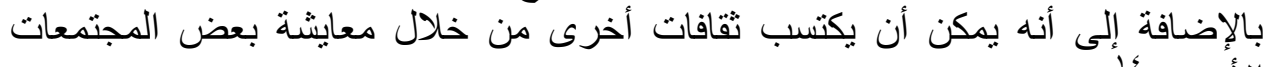

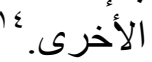

و عليه فالمغزى الأساس من هذا أنه عندما نضع مناهج تعليم اللغة العربية للناطقين

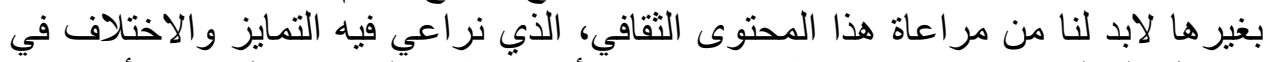

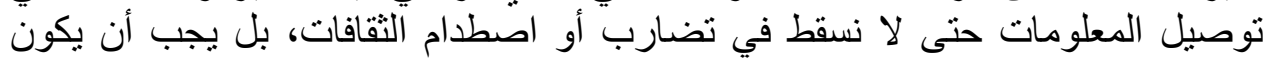

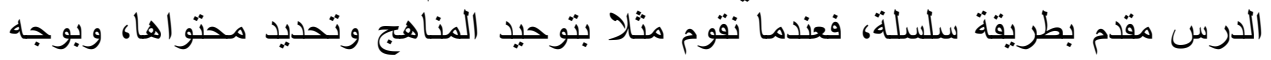

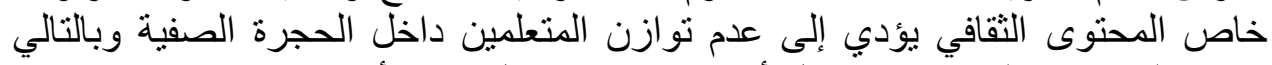

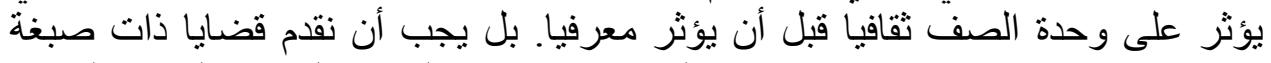

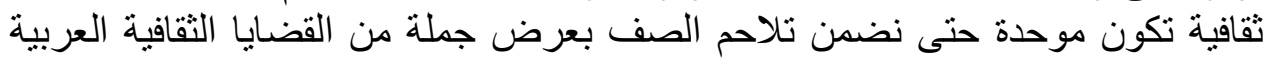

$$
\begin{aligned}
& \text { مثل: } \\
& \text { ا - الخط العربي } \\
& \text { r- ا- الأدب العربي } \\
& \text { ك- ـ نوادر وطر ائف عربية } \\
& \text { عـ الأسواق العربية }
\end{aligned}
$$

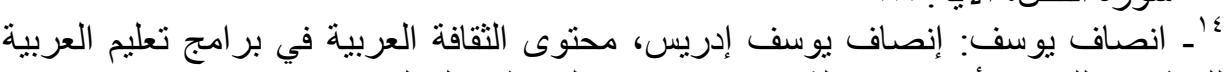

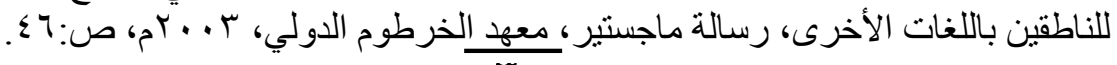




$$
\begin{aligned}
& \text { هـ ــ الطعام العربي } \\
& \text { 7- الرياضة العربية }
\end{aligned}
$$

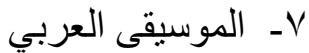

$$
\begin{aligned}
& \text { 1ــ الموشحات الأندلسية } \\
& \text { جـ ـ عادات وتقاليد الثعوب العربية }
\end{aligned}
$$

خاتمة ونتائتج

بعد الدراسة في أهم ما يكتنف المنهج من مشاكل تعترض تعليم اللغة العربية

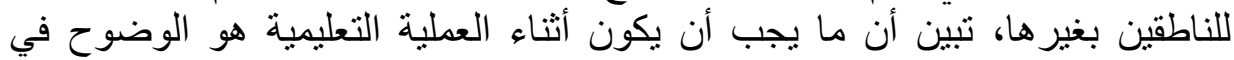

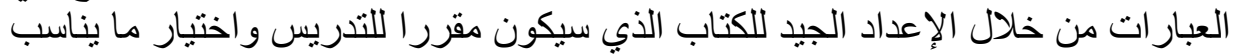

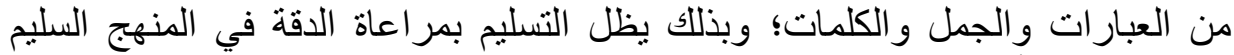

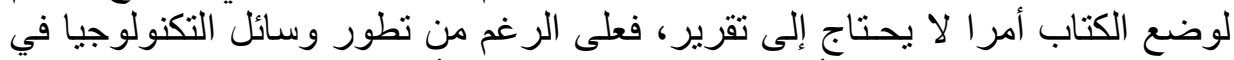

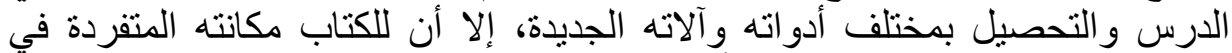

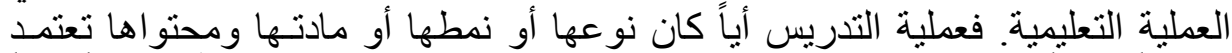

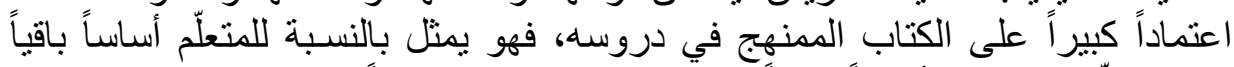

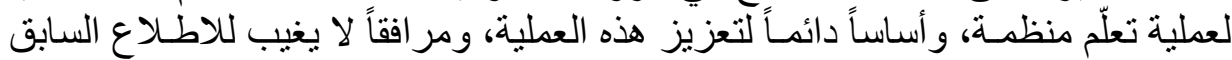

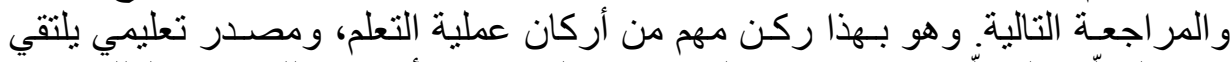

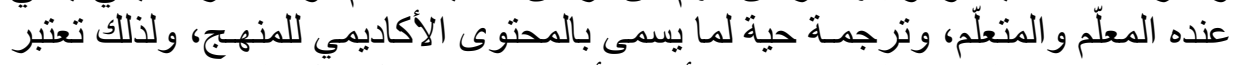

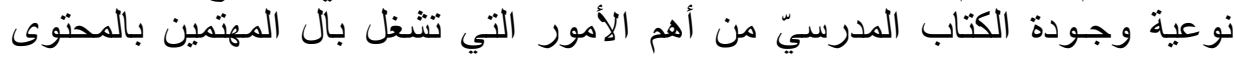
والمسادة التعليمية وطريقة الكيابة التدريس.

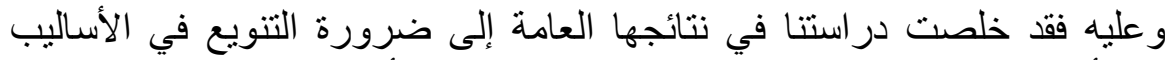

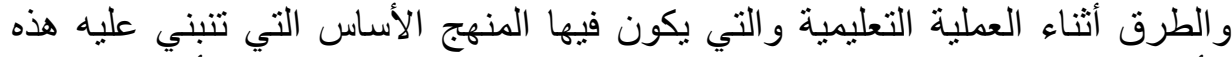

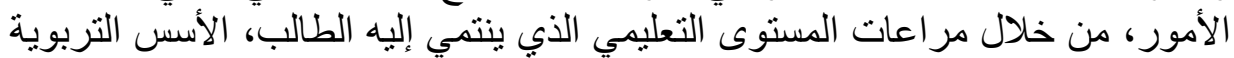

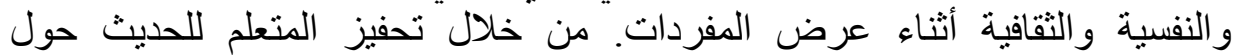

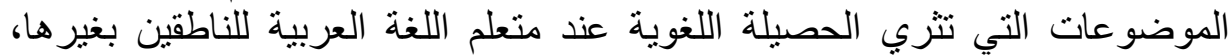

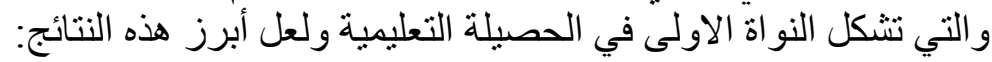

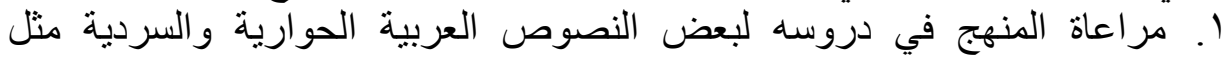
r. الاعتماد على القصص التمثيلة القصيرة باللغة العربية والتي تراعي التنوع في الشخصيات (رجل، امر أة، طفل). r. الحديث عن المدرسة ومكوناتها.

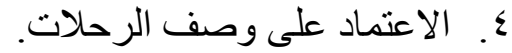

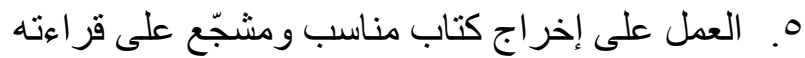


7 7. أن يكون منهج الكتاب مناسب للبرنامج الذي يختاره المعلم لمتعلميه حتى تتحقق العملية التعليمية منية 


\section{لائحة المصادر والمراجع المعتمدة}

$$
\text { القرآن الكريم }
$$

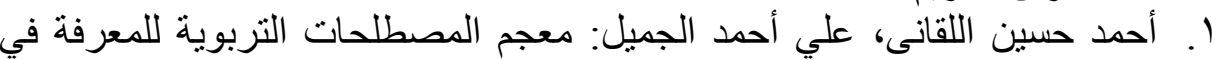

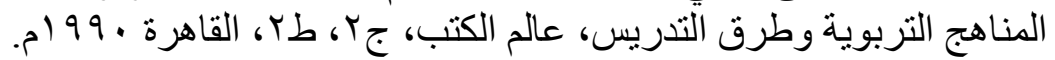

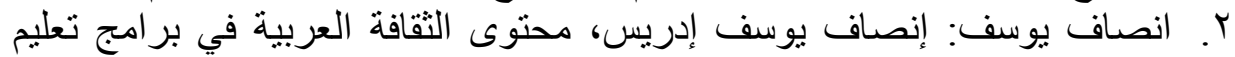

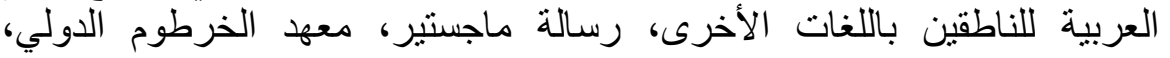

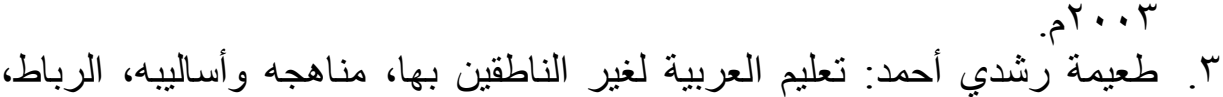

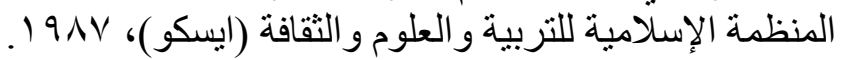

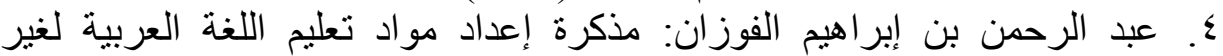

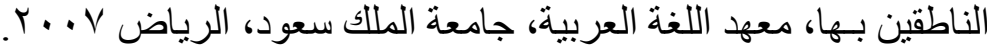

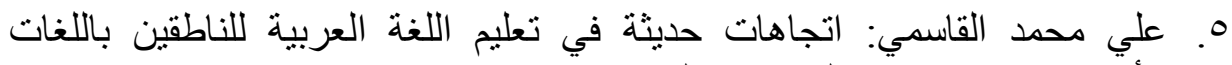

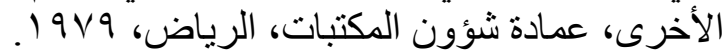

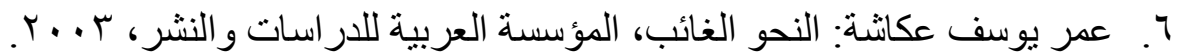

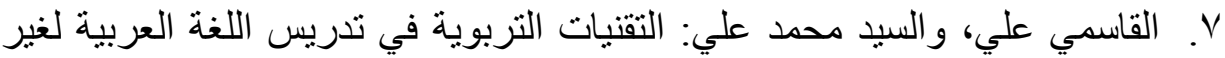

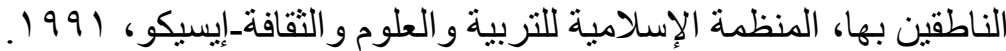

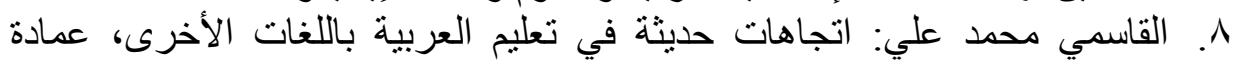

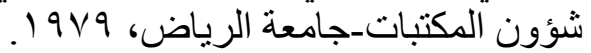

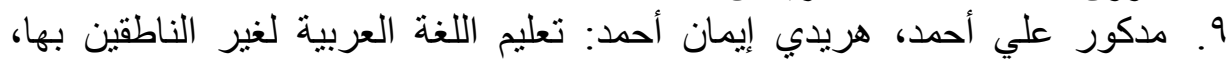

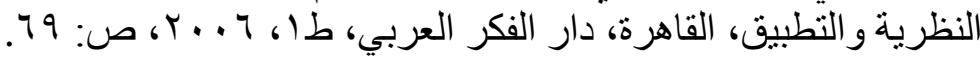
10. Oxford, R. L: Task-Based Language Teaching and Learning: An Overview. 2006. 